\title{
Topographical factor-based shallow landslide hazard assessment: a case of Dayi area of Guizhou Province in China
}

\author{
Bin Yu, Yunbo Zhu and Yang Liu
}

\begin{abstract}
Background: Three groups of factors related to topography, geology and hydrology have influence on the triggering of shallow landslides in soil material. In this paper a single representative factor ( $T$-factor) for the topography is proposed, which can be used to define threshold values for the possibility of shallow soil slides. This study was carried out in the Dayi area, Guizhou Province, China. During a heavy rainfall event on June 6, 2011, 230 shallow soilslides were triggered. In some slopes, no shallow landslides were triggered even though some of the topographical factors point to unstable high probability.

Results: We isolated and analyzed the influence of the topography on the triggering of shallow landslides in catchments with almost identical hydrological and geological conditions and propose a new $T$-factor as a topographical indicator which is a combination of the slope angle, the upslope contributing area, the cross-section, and the free-face of a (potential) shallow landslide. Higher T-factor values are related to higher probabilities of shallow landsliding. The probability assessment with the topographical factor $T$ was successfully validated in other areas of the USA and Japan.

Conclusions: Without information on the geological and rainfall conditions, a quick and primary prediction of shallow landsliding using the topographical factor $T$ is proposed. Additionally a new $R$-factor is proposed as a rainfall indicator, which is a combination of the 1 hour rainfall and cumulative rainfall before the landslide event and the annual rainfall. Higher $R$-factor values are generally related to higher probabilities of shallow landsliding. The primary probability factor $P$, which is the combination of $T$ and $R$, gives a final indication of the probability of shallow landsliding.
\end{abstract}

Keywords: Topographical threshold factor, Rainfall threshold factor, Shallow landsliding, Dayi catchment

\section{Background}

Shallow landslides are common in mountainous areas after intense rainfall or long term rainfall. They are natural phenomena that pose a serious natural hazard in many countries. Shallow landslides cause not only considerable financial losses but also major ecological and environmental problems such as increased soil erosion rates and overload of sediments in rivers downstream. Shallow translational landsliding is the most commonly observed failure mode in soil material (Meisina and Scarabelli 2007). The occurrence of these landslides is controlled by various spatial and climatic factors, such as geology, topography, hydrogeological

\footnotetext{
* Correspondence: 471174592@qq.com

State Key Laboratory of Geohazard Prevention and Geoenvironment Protection, Chengdu University of Technology, Chengdu 610059, China
}

conditions, vegetation and rainfall. Thus, prediction of landslide susceptibility is difficult because an enormous amount of spatial data must be acquired from the region and processed (Park et al. 2013). No one, however, takes full advantage of the fact that shallow failures are, in general, strongly controlled by surface topography (especially lateral concavity) through shallow subsurface flow convergence and increased soil saturation by infiltration of water (Borga et al. 2002).

The shallow landslides are mainly influenced by topographical factors: slope gradient (a very sensitive factor) and lateral concavity in relation to the upstream contributing area which induced convergence of subsurface water flow, increase in groundwater height and hence decrease in slope stability. As hydrological processes are considered to have a major influence on slope stability, 
the occurrence of landslides is thus controlled twofold by slope gradient and lateral concavity (Hennrich and Crozier 2004).

Although in these studies topography has been reported as an important factor for slope stability, only slope angle is considered as the topographical factor in most stability models (Talebi et al. 2008). Slope angle is probably the main factor for stability as it affects the magnitude of both normal stress (determining the mobilized shear resistance) and the driving shear stress on the potential surface of failure. Therefore almost all statistical models include slope angle as a topographical factor (Baeza and Corominas 2001). However, slope angle is not the only topographical factor for the initiation of shallow landslides. Take for example the position on a slope: the further upslope from the base of a hillslope, the faster a site will drain. Likewise, slope sites with hollows usually drain much more slowly than sites on ridges. The free-face of a slope is also an important factor because it provides an open and immediate outlet of the landslide.

O'Loughlin (1986) and Montgomery and Dietrich (1994) developed a physical model for the topographic control on shallow landsliding. The model divides a catchment into topographic elements defined by the intersection of contours and flow tube boundaries orthogonal to the contours. The slope gradient and the upslope contributing area of a shallow landslide were considered as the topographical factors in their model. Montgomery and Dietrich (1994) pointed out that steep slopes and topographic hollows which concentrate the surface and subsurface water to the outlet are the most susceptible to failure. Baeza and Corominas (2001) pointed to the important influence of a cross-section perpendicular to the slope gradient, on the initiation of shallow landslides. The cross-section of the slope (lateral convexity or concavity) shows the ability of the topography to disperse or concentrate water at a certain location, which has a large effect on the susceptibility to landsliding.

Based on the findings mentioned above Baeza and Corominas (2001) used the slope, the upslope contributing area and the cross-section of the slope, for the assessment of shallow landslide susceptibility. However, the influence of the presence of a free-face at the toe of a (potential) landslide may also play an important role.

In this study, we focus on the shallow landslides occurred in soil (also called shallow soil slips). These shallow landslides provided an unprecedented amount of data to obtain a combined topographical factor. By focusing on the process mechanisms our aim was to find a significant and probably more general relationships between the likelyhood of shallow landsliding and one single combined topographic factor.

\section{Study area}

Many shallow landslides on slopes covered with soil were triggered in the Dayi catchment Guizhou Province, China by a rainstorm on June 6,2011 . They were most $0.5-1 \mathrm{~m}$ in depth and a few meters long by a few meters wide. Some of these triggered debris flows (see Fig. 1, Yu et al. 2016). The groundwater level is lower than the lower boundary because the slips were triggered in the middle or up part of the slopes, and the groundwater level is in the bottom part of the slopes.

The Dayi catchment is located in the upstream area of the Wangmo River. The Wangmo River is a main tributary of the Nanpanjiang River, which is a tributary of the Zhujiang River, the third largest river in China. The Wangmo River flows in a North- South direction. The lowest elevation in the Dayi catchment is $710 \mathrm{~m}$, and the highest peaks in the catchment have altitudes between 1500 and $1600 \mathrm{~m}$. The hill slope gradients in the catchment are very large, most of them are larger than 20 degrees. These are suitable topographic conditions for triggering shallow landslides.

Only two lithological units are exposed in the study area: hard siltstone interbedded with thin mudstone. The thickness ratio of siltstone and mudstone is $3-4$ to 1 . There is no faulting in the study area. The shallow landslides occurred in soil material on the slopes. The geological conditions for the triggering of shallow landslides in the study area are almost identical.

The average annual rainfall lies in the range between 1190 and $1320 \mathrm{~mm}$, and the average annual temperature varies between 14.4 and $16{ }^{\circ} \mathrm{C}$. Figure 2 shows the rainfall data of the Dayi and Xintun (13.1 km south of Dayi) meteorological stations, before and after the occurrence of the shallow landslides on June 5 and 6, 2011. The rainfall started at 22:00 h, June 5, at the Dayi station, but there was almost no rainfall at the Xintun station until 01:00 h, June 6 . The maximum rainfall intensity in $1 \mathrm{~h}$ was $105.9 \mathrm{~mm}$ at the Dayi station from 23:00 to 24:00, June 5

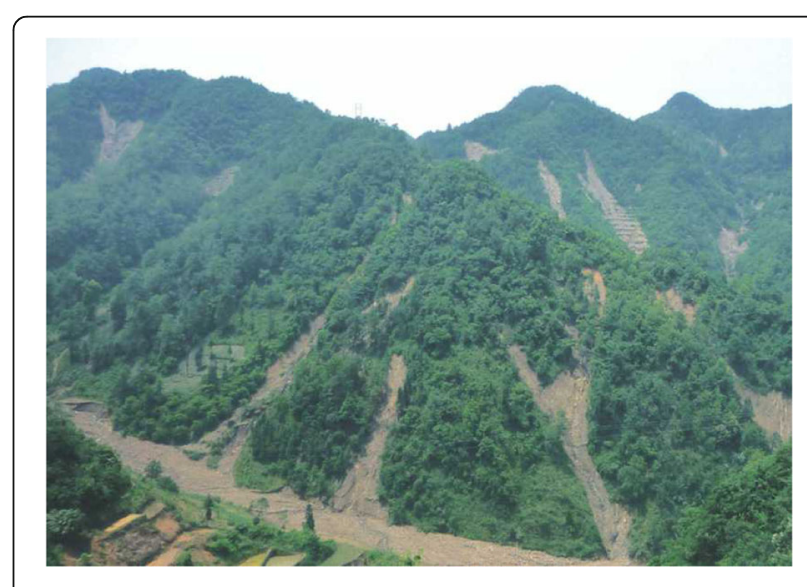

Fig. 1 Shallow landslides near Dayi, Guizhou Province, on June 6, 2011 


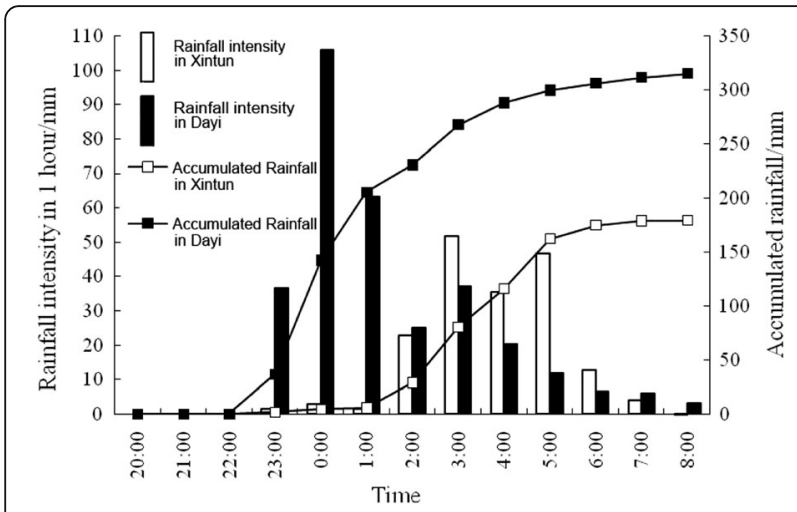

Fig. 2 Rainfall in the Dayi area on June 5 and 6, 2011 (see Fig. 2). The debris flows were triggered between 23:00, June 5 and 04:00, June 6 and the shallow landslides may be triggered also in this period (Yu et al. 2016).

Because the rainfall of June $5-6$ showed a variation from north to south, the study area was divided into 4 sub-areas from north to south. The triggering times of debris flows caused by shallow landslides were between 1:00 and 2:00 o'clock in the sub-areas 1 and 2, between 3:00 and 4:00 o'clock in sub-area 3, and between 4:00 and 5:00 o'clock in sub-area 4 (Fig. 3).

Field investigations were conducted upstream and downstream of Dayi town. The topographical factors were investigated for 230 shallow landslides, and 138 potential unstable slopes. These potential unstable slopes have a large slope gradient or a gentle upslope gradient in the longitudinal section, or a large degree in lateral concavity or a free-face of slope in the longitudinal

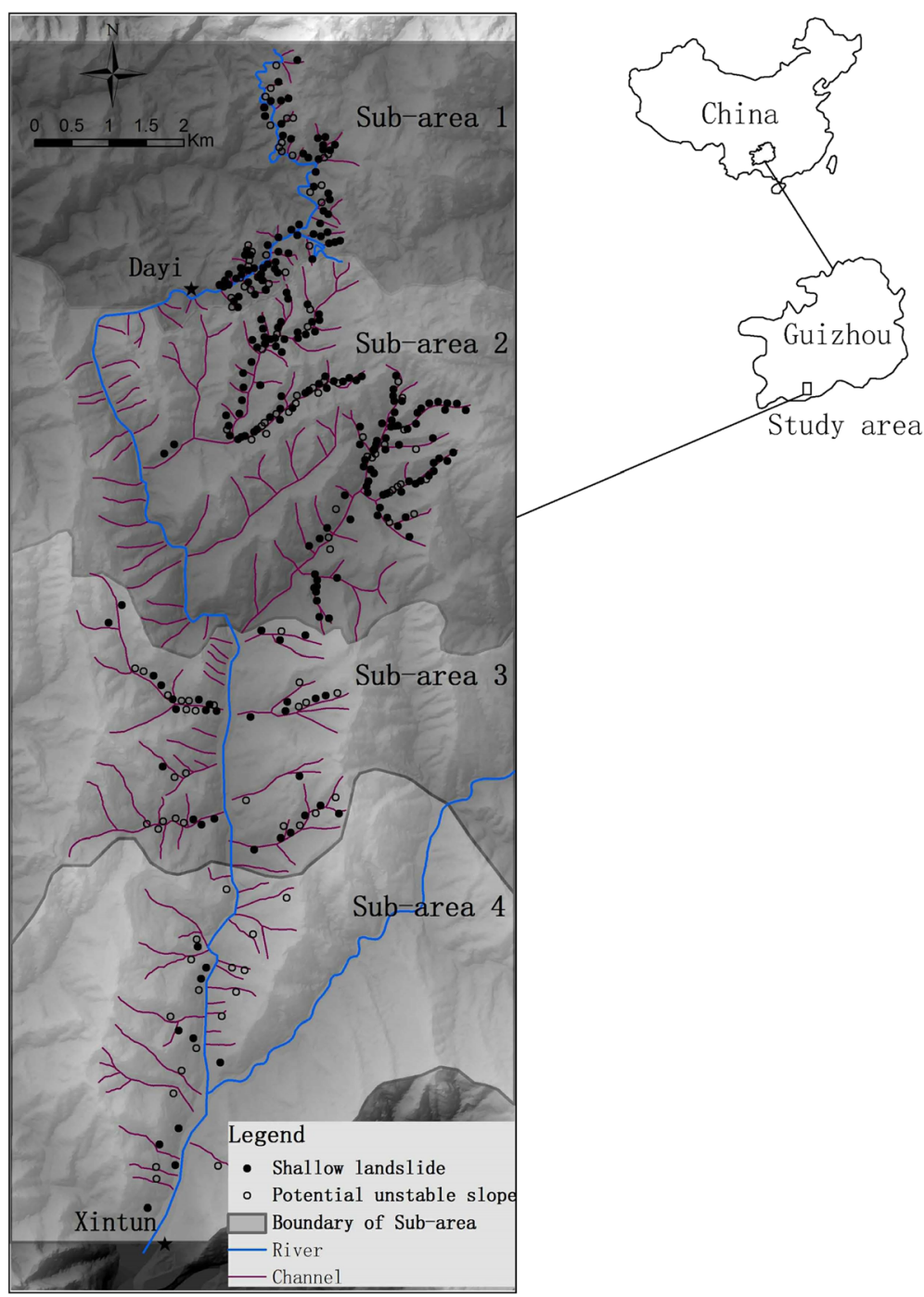

Fig. 3 The shallow landslides and potential unstable slopes with the investigated sub-areas in the Dayi area, Guizhou Province 
section, or a combination of two or more out of four of these characteristics. Figure 3 shows the location of the 230 shallow landslides, and 138 potential unstable slopes. The drainage areas of sub-area 1, 2, 3, and 4 are $16.9 \mathrm{~km}^{2}, 30.3 \mathrm{~km}^{2}, 11.5 \mathrm{~km}^{2}$, and $27.6 \mathrm{~km}^{2}$, respectively. The percentage of the slope which the slope gradient between 20 degree and 50 degrees are $72.7 \%, 64.1 \%$, $80.3 \%$, and $66.6 \%$, respectively. The slope is very steep in the right bank in sub-area 2 . The percentage of the slope which the slope gradient more than 50 degrees is $32.5 \%$ in the right bank of sub-area 2. But the percentage of the slope which the slope gradient more than 50 degrees is only $4.1 \%$ in the left bank of sub-area 2 . The slope gradient is too large to keep the soil in the right bank of sub-area 2. So there is no soil slip in the right bank of sub-area 2. The topographical characteristics of the 368 slopes without and with shallow landslide triggered on June 6, 2011 in the Dayi area were obtained from the field investigations. The investigations in the sub-area 1 were only conducted along the river banks or less than $500 \mathrm{~m}$ along the channel in the catchments because these is no way to go into the upstream of catchments. There are 37 gullies were found gully-type debris flows cause by shallow landslides (Yu et al. 2016). According to $\mathrm{Yu}$ et al. (2016), the major topographic factors related with the occurrence of debris flows by shallow landslides are the gradient of the stream channels, the area ratio of the catchment with terrain slope angles between 25 degree and 45 degree, and the size of the catchments. The role of the terrain slope angles is far more important than the role of the size of the catchment, and the role of the average gradient of the stream channels. The probability of debris flow formation caused by shallow landslides increases with increasing of the topographical factor which is a combination of the factors of the gradient of the stream channels, the terrain slope angles, and the size of the catchments (Yu et al. 2016). In these gullies with debris flows cause by shallow landslides, 112 shallow landslides were found. The average value of shallow landslide in the debris flows is 3.03 . But the average value of shallow landslide in the 63 catchments without debris flow is 1.87 . The average percentage of the slope which the slope gradient between 25 and 45 degrees is $66.4 \%$ for the 37 gullies, but the average percentage of the slope which the slope gradient between 25 and 45 degrees is $48.3 \%$ for the other gullies without debris flows in Fig. 3. The average topographical factor is 0.338 for the 37 gullies, but the average topographical factor is 0.237 for the other gullies without debris flows in Fig. 3.

\section{Methods}

In Fig. 3, the maximun N-S width is about $4 \mathrm{~km}$ in each sub-aera. Due to the relative small size of each sub-area, and the same triggering time of shallow landslides, the rainfall conditions are assumed to be uniform for the slopes within that sub-area. Therefore we can assume that only the topography is the dominant factor for the triggering of shallow landslides within each sub-area.

The most important topographic factor which plays a role in controlling the stability of shallow landslides is the slope angle (Mulder 1991). Figure 4 shows the other major important topographic factors: the upslope gradient in the longitudinal section, the sides of the hollow in the crosssection, and the free-face of the slope also in the longitudinal section (O'Loughlin 1986; Montgomery and Dietrich 1994; Baeza and Corominas 2001).

It is easy to find and measure the parameters in Fig. 4 for existing landslides. But for the potential landslides, one must firstly detect the body of the potential landslide. According to the important topographical factors mentioned above, the largest slope gradient, gentle upslope gradient in the longitudinal section, the hollow in the cross-section, and the free-face of the slope in the

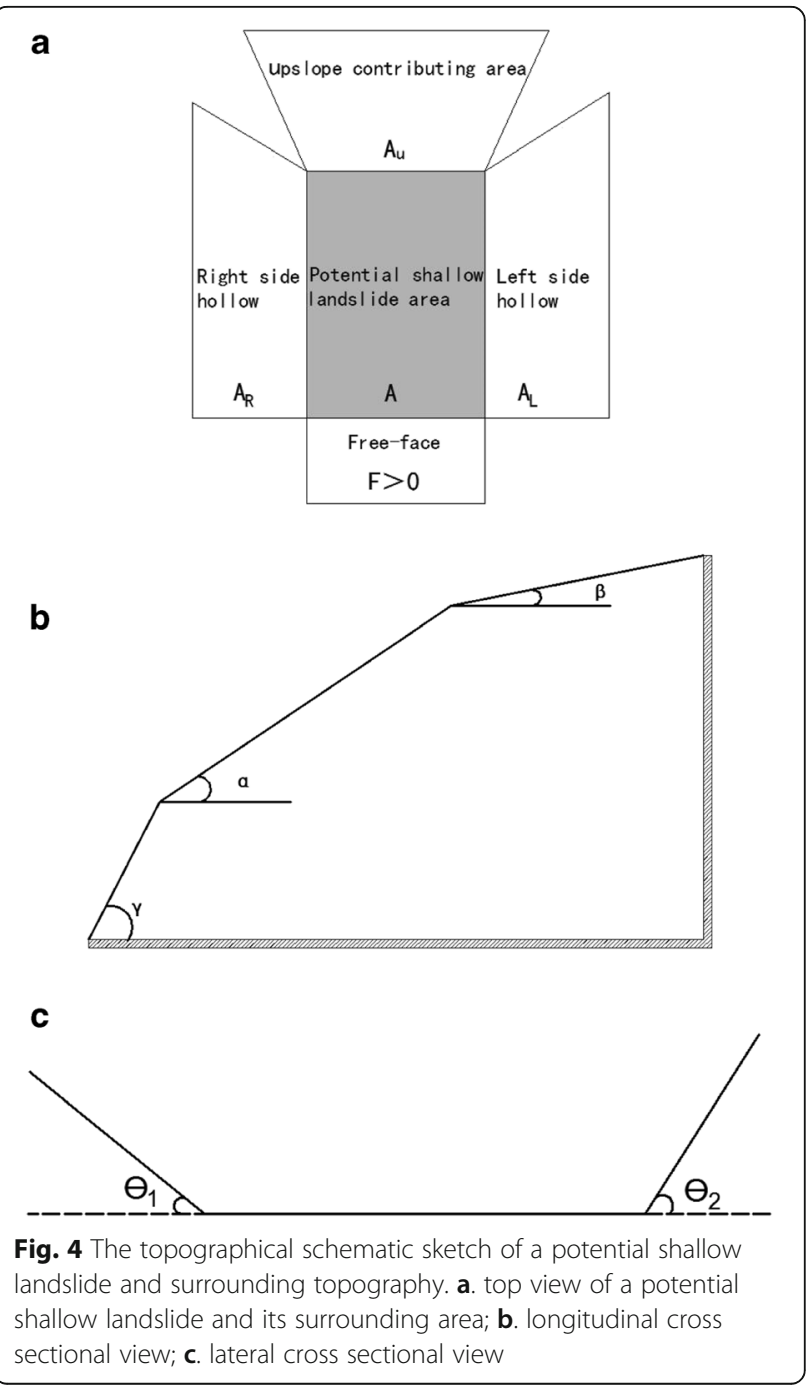


longitudinal section are the key points to detect potential shallow landslides. To identify a potential shallow landslide one can start with the selection in the longitudinal section of a large slope gradient. Then one can connect this section with a gentler upslope gradient, or with a hollow in a cross-section, or a free-face of the slope in the longitudinal section, or a combination of two, or three of these important topographical factors. Some slopes without a large slope gradient, but with the presence of a gentler upslope gradient in the longitudinal section, or hollows in a cross-section, or a free-face of the slope in the longitudinal section are also chosen as potential shallow landslides.

In Fig. 1, a slope with cross-section a hollow (lateral concavity) may be first selected as a potential shallow landslide. The top boundary of $A$ is the knick point with the gentler upslope. If there is no knick point with the gentler upslope, the top boundary of $A$ is the top end of the hollow in cross-section. The bottom boundary of $A$ is the knick point with the free-face of the slope. If there is no knick point of the free-face of the slope, the bottom boundary of $A$ is the end of the hollow in crosssection. The left side and right side boundaries of $A$ are the boundaries of the flat part between the hollows in cross-section (see Fig. 1). The top boundary of $A u$ is the knick point of the gentler upslope or the top of the slope. The left side and right side boundaries of $A u$ are the edges of the upstream contributing area which induced convergence of subsurface water flow (see Fig. 1). The bottom boundaries of $A_{R}$ and $A_{L}$ are at the same level of the bottom boundary of $A$. The top boundaries of $A_{R}$ and $A_{L}$ are the edges of the lateral concavity which induced convergence of subsurface water flow. The left boundary of $A_{L}$ or the right boundary of $A_{R}$ is the outside edge of the hollow (see Fig. 1).

The differences between the gully and a slope corresponding to a landslide area in Fig. 1 include the following: a) The slope angle of shallow landslides have larger gradients, while the slope angles of gullies may be more gentle in most sections (see Fig. 1). b) The shallow landslides are a few meters long and a few meters wide, but the gullies may be up to $1 \mathrm{~km}$ long and tens of meters in width (see Fig. 1). c) The shallow landslides may occur at the heads of the first-order gullies (Montgomery and Dietrich 1994). At these heads the gullies may have the same topography as the slopes corresponding to the landslide areas with large slope angles, a few meters in length and a few meters in width.

\section{Slope angle factor}

The slope angle of a shallow landslide is one of the most important triggering factors because it provides the driving force of a slide. That is why all models include slope angle as a topographical factor (Baeza and Corominas 2001). Most shallow landslides are triggered on slopes between 20 and 40 degrees (Wang 1999). If the slope gradient is too large (more than 45 degrees), less shallow landslides will be triggered because the soil thickness is too thin (Montgomery and Dietrich 1994). If the slope gradient is less than 20 degrees, less shallow landslides will be triggered because the slope is too gentle (Godt et al. 2008). The slope angle factor $S$ can be defined as:

$$
S=\tan \alpha
$$

in which $\alpha$ is the slope angle of the shallow landslide (Fig. 4).

\section{Upslope factor}

The the upslope contributing area draining towards the shallow landslide (Fig. 4) were considered as topographical factors in the model of O'Loughlin (1986), Montgomery and Dietrich (1994). Wieczorek et al. (2007) indicated that an upslope drainage area with a gentler slope gradient triggered more shallow landslides because drainage is slower than on steeper slopes. This will increases the groundwater water storage in the potential landslide area and hence the probability of failure. Also a larger upstream drainage area increases the chance for slope failure for the same reason. The upslope drainage factor can be defined as:

$$
U=\frac{A_{u}}{A} \tan (\alpha-\beta)
$$

In which: $U$ is the upslope drainage factor; $A_{u}$ is the area of upslope drainage area $(\mathrm{m}) ; A$ is the area of a (potential) shallow landslide, $A$ is referred to the source area only; $\beta$ is the slope angle of an upslope drainage area.

The upslope factor $U$ reflects also the role of a gentler upslope gradient on the triggering of shallow landslides. If the upslope angle $\beta$ is larger than the slope angle $\alpha$, the slope drains much faster, and the effect of the upslope drainage area on shallow landsliding is much lower than the effect of a gentler upslope gadient. To simplify our research, the upslope factor $U$ is set to 0 if the upslope angle $\beta$ is larger than the slope angle $\alpha$. This simplification does not mean that there is no contribution of a steep upstream area to slope failure, but the contribution is less.

\section{Cross-section factor}

The cross-section of the slope shows the ability of the topography to disperse or concentrate water to the potential landslide area, which can become less or more susceptible to landsliding (Baeza and Corominas 2001). Montgomery and Dietrich (1994) indicated that the lower end of topographic hollows is predicted to be susceptible to failure. The sites of the hollows usually drain much more slowly 
than sites on ridges because the hollows can concentrate water. The cross section factor can be defined as:

$$
C=\frac{A_{L}}{A} \tan \theta_{1}+\frac{A_{R}}{A} \tan \theta_{2}
$$

in which: $C$ is the cross section factor; $A_{L}$ is the area of the left side $(\mathrm{m}) ; A_{R}$ is the area of right side $(\mathrm{m}) ; \theta_{1}$ is the slope angle of the left side in cross-section; $\theta_{2}$ is the slope angle of right side in cross-section (Fig. 4) .

The cross section factor $C$ represents the effect of a lateral concavity or hollow on the triggering of shallow landslides. When the slope angle $\theta_{1}$ or (and) $\theta_{2}$ is (are) less than zero, in other words: in case of a lateral convexity of the slope, the ratio of $A_{L} / A$ or (and) $A_{R} / A$ is (are) set to zero. In this way we reduce the effect of lateral concavity to zero.

\section{Free-face factor}

The free-face is the necessary condition for the initiation of a rock slide. For the shallow soil slides, the free-face is not necessary because the toe of the slide may shear out from the soil layer as a so called slope failure. However a free-face (like a road cut) makes the slope more susceptible to failure but is not a prerequisite for shallow soil failure. When the downslope angle $\gamma$ in Fig. 4 is larger than slope angle $\alpha$, there is a free-face. If $\gamma>\alpha$, then the free-face factor $F$ will be taken into account: $F>0$, otherwise $F=0$. The value of $F$ is determined by field investigations (see below).

\section{Results: the topographical factors in the study area, and their role in the triggering of shallow landslides}

To obtain the topographical factor of shallow landslides with the sub-factors $S, U, C$, and $F$, the mutual relationships between these facors have to be established first.

\section{The relationship between the slope angle $S$ and upslope factor $U$}

To obtain the relationship between the slope angle factor $S$ and the upslope factor $U$, a comparison between shallow landslides and stable slopes is needed with the same value of the cross-section factor $C$ and free-face factor $F$. The topographic data in which $C=0$, and $F>0$ (free-face is available) is satisfying this condition. And the comparison should be in one sub-area because the rainfall condition is almost the same in each sub-area. Figure 5 a. to $\mathrm{d}$. shows the relationship between the slope angle factor $S$ and the upslope factor $U$ in sub-area 1 to 4 of Fig. 3. Generally all figures show that with increasing value of $S$ and $U$ the chance of shallow landslide failure also increases. But there are minimum values for $S: 0.33,0.36,0.39$, and 0.41 , respectively in sub-area 1,2, 3, and 4. No shalllow landslide will be triggered below these minimum $S$ threshold values irrespective of the value of $U$. By separating the data with shallow landslides and without shallow landslides, a factor $T_{1}$, which is a measure for the possibility of shallow landsliding in Fig. 5 can be obtained:

$$
T_{1}=S+1.8 U \geq C_{r 1}
$$

in which $T_{1}$ is the factor; $C_{r 1}$ is the critical value for triggering shallow landslides.

The critical value $C_{r 1}$ is $0.60,0.65,0.70$, and 0.73 , respectively in sub-area $1,2,3$, and 4 . To trigger a shallow landslide, the slope angle factor $S$ must be large or equal to $0.33,0.36,0.39$, and 0.41 , respectively in sub-area $1,2,3$, and 4 . The reason for an increase of the critical value $C_{r 1}$ and the minimum slope angle $S$ from north to south is the rainfall which was decreasing from north to south. Conversely we can imagine that for large rainfalls, the critical value and the minimum slope angle for triggering shallow landslides are reducing.

Figure 5 shows that the threshold line $S+1.8 U=C_{r 1}$ can separate slopes with shallow landslides from slopes without shallow landslides exactly. The triggering probability of shallow landslides increases with increasing $T_{1^{-}}$ values in each sub-area.

The relationship between the slope angle $S$ and cross-section $C$ To obtain the relationship between the slope angle factor $S$ and the cross-section factor $C$, we compared shallow landslides and stable slopes with the same value of the upslope factor and free-face factor. The topographical data with $U=0$, and $F>0$ (free-face is available) is satisfying this condition. In Fig. 6 a. - d. a scatter plot of landslides and stable slopes is now made in a $S-C$ field for each sub-area.

All figures show again the posive effect of a larger slope angle factor $S$ and cross-section factor $C$ on the possibility of triggering shallow landslides. Minimum values for $S$ below which no landslides can occur at all are: $0.33,0.36,0.39$, and 0.41 , respectively in sub-area 1 , 2,3 , and 4 . By separating the data with shallow landslides and without shallow landslides in the $S$-C field, a factor $T_{2}$ from Fig. 6 can be obtained:

$$
T_{2}=S+0.8 C \geq C_{r 2}
$$

in which $T_{2}$ is the factor; $C_{r 2}$ is the critical value for triggering shallow landslides.

The critical value $C_{r 2}$ is $0.60,0.65,0.70$, and 0.73 , respectively in sub-area $1,2,3$, and 4 . To trigger a shallow landslide, the slope angle factor $S$ must be large or equal to $0.33,0.36,0.39$, and 0.41 , respectively in subarea $1,2,3$, and 4 . Here again we see the effect of the 

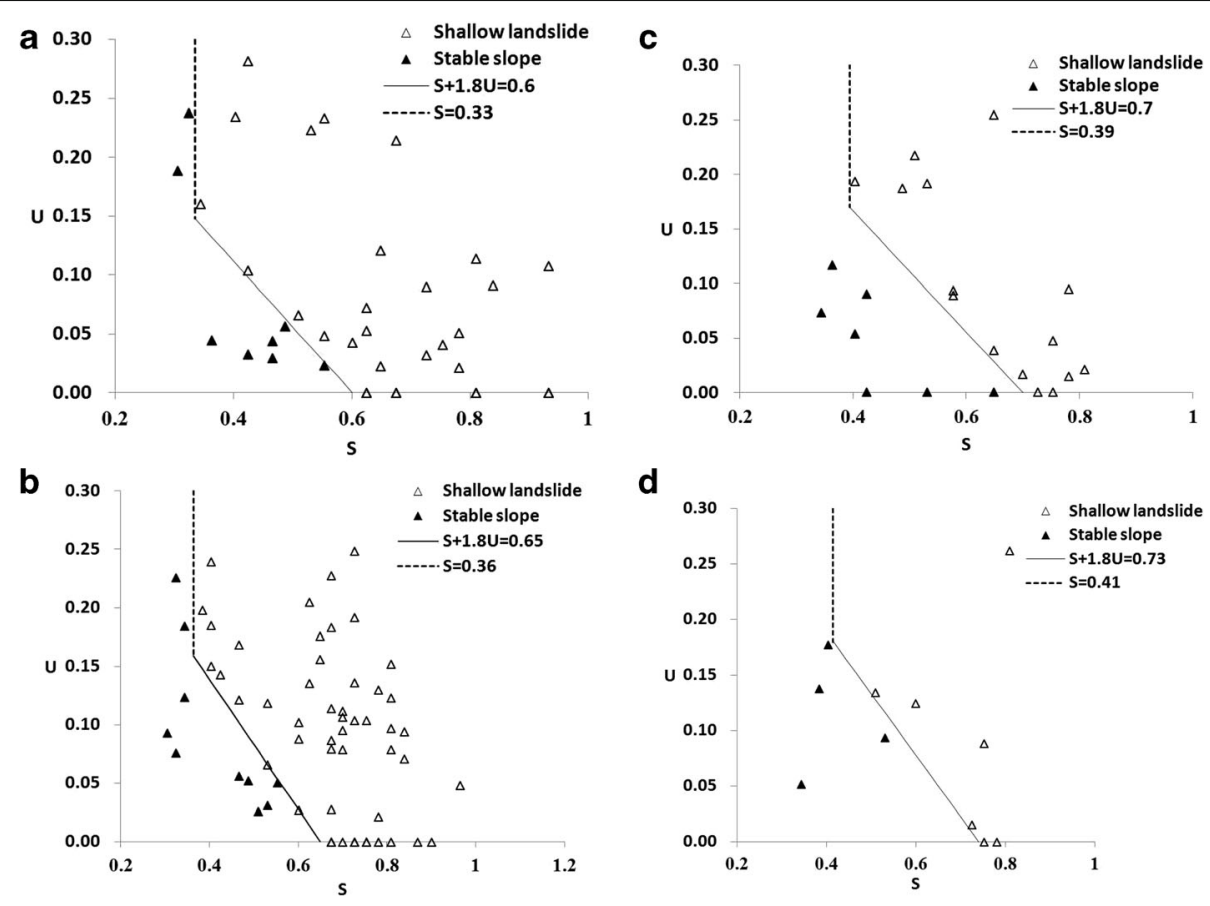

Fig. 5 The relationship between the slope angle factor $S$ and upslope factor $U$. a. Sub-area 1; b. Sub-area 2; c. Sub-area 3; d. Sub-area 4

decreasing rainfall from North to South on the increase of the $C_{r 2}$ and $S$ values.

Figure 6 shows that the line $S+0.8 C=C_{r 2}$ can completely separate slopes with shallow landslides from slopes without shallow landslides. The probability of shallow landsliding increases with increasing $T_{2}$-values in each sub-area. The role of the slope angle factor $S$ seems to be more important than the role of the cross-section factor $C$.

\section{The role of the free-face}

From Eqs. 4 and 5, one can combine the relationship of the slope angle factor $S$, the upslope factor $U$, and the cross-section factor $C$. A factor $T_{3}$ for triggering shallow landslides can be obtained:

$$
T_{3}=S+G=S+1.8 U+0.8 C \geq C_{r 3}
$$

in which $T_{3}$ is the factor; $G$ is the factor combining the role of the upslope factor $U$, and the cross-section factor $C ; C_{r 3}$ is the critical value for triggering shallow landslides.

To analyze the role of the free-face factor $F$, all investigated landslide and stable slope sites were were plotted for the sub-area 1 to 4 in Fig. 7 a. - d., with as horizontal axis the slope angle factor $S$ and as vertical axix the combined factor $G$. As we can expect increasing values of $S$ and the the combined factor $G$ has a positive effect on the probability of shallow landslide failure. Minimum values for $S$ below which no landslides can occur whatever the value of $G$ are: $0.33,0.36,0.39$, and 0.41 , respectively in sub-area $1,2,3$, and 4 with or without the free-face factor $F$. The critical value $C_{r 3}$ is $0.60,0.65$, 0.70 , and 0.74 , respectively in sub-area $1,2,3$, and 4 for a free-face $(F>0)$ and $0.73,0.78,0.83$, and 0.87 for sites without a free-face $(F=0)$ (Fig. $7 \mathrm{a}-\mathrm{d})$. So larger $T_{3^{-}}$ values are needed to trigger shallow landslides in case of the absence of a free-face. The role of the free-face factor is the difference of the critical values with and without a free-face factor. One can obtain the free-face factor: $F=0.13$ in case of a free-face, and $F=0$ in case of absence of a free-face.

\section{The topographical factor $T$}

The slope gradient may be too large to trigger shallow landslides because there is almost no soil (Montgomery and Dietrich 1994). Frattini et al. (2009) indicated that slopes are unconditionally stable if the gradient is larger than $52.5^{\circ}(S=1.3)$. In the study area, the maximum $S$-value for shallow landsliding is $1.07\left(47^{\circ}\right)$. The maximum $S$-value may be larger than 1.07 in case of larger rainfall amounts and soil material more prone to shallow landsliding than the soils in this study. In accordance with Frattini et al. (2009), the maximum slope gradient for landsliding is set at 1.3.

Slope angle should be more important than the upslope factor $U$ and cross-section factor $C$, or the combined factor $G$. Based on our data base the maximum G-value is as large as 1.6 (Fig. 7 c), while the 


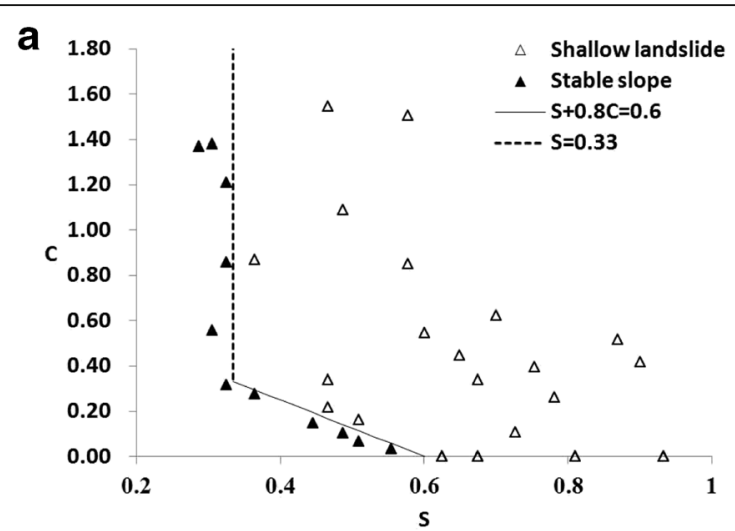

b

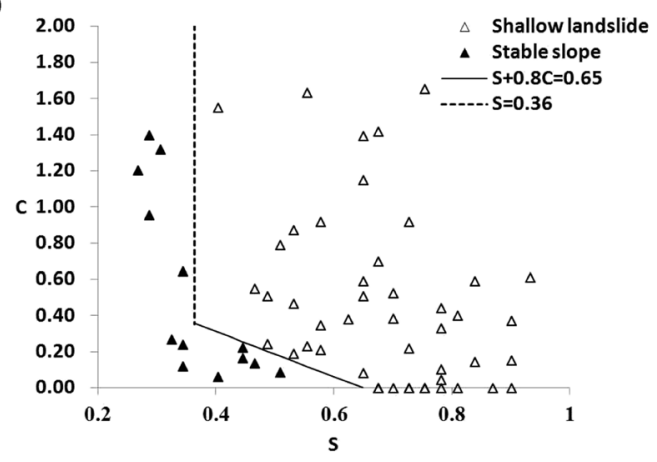

C

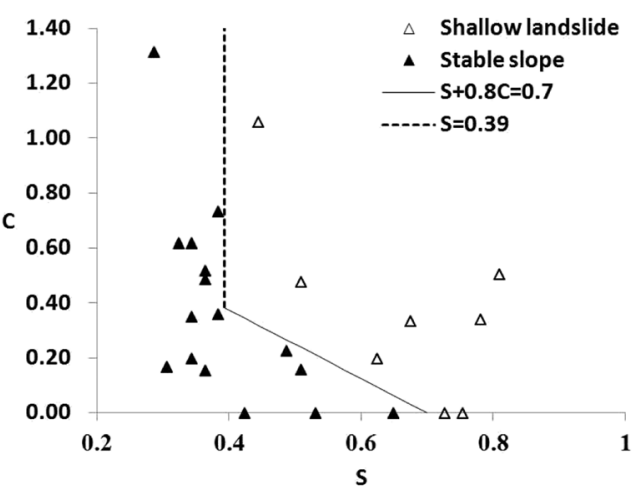

d

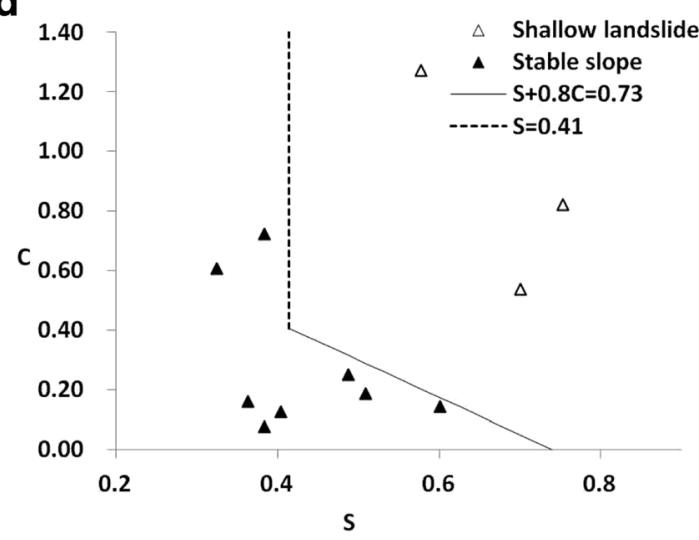

Fig. 6 The relationship between the slope angle factor $S$ and cross-section factor C. a. Sub-area 1; b. Sub-area 2; c. Sub-area 3; d. Sub-area 4 maximum $S$-value is only 1.07 in Fig. 7. Shallow landslides will not be triggered if the slope angle factor $S$ is less than its minimum value regardless the value of the combined factor $G$ in each sub-area. So the $G$-value has a limited role for the triggering of a shallow landslide. A limitation for the $G$ factor is needed for the topographical factor.

The points of intersection of the critical line of no free-face and the minimum slope angle factor $S$ are 0.39 , $0.42,0.44$, and 0.46 for the $G$-value (Fig. 7). If the Gvalue is larger than these intersection points and the slope angle factor $S$ is less than the minimum value in each sub-area, the $G$-value plays no role because there is still no shallow landslide triggered. To simplify the topographical factor $G$, a fixed maximum value for $G$ may be used which is the maximum value of the intersection points of the 4 sub-area: 0.46 (Fig. $7 \mathrm{~d}$ ). If the maximum $G$-value is obtained from the critical line of the "freeface landslides" instead of the critical line of "no freeface landslides" the limited G-value in that case is 0.33 . To simplify the research work, the limited value for the combined factor $(G+F)$ is chosen as 0.46 . Then the modified topographical factor can be obtained as:

$$
\begin{aligned}
& T=S+G+F=S+1.8 U+0.8 C+F \geq C_{r} \\
& G+F=1.8 U+0.8 C+F \leq 0.46
\end{aligned}
$$

$F=0$, when free-face is absent

$$
F=0.13, \text { when free-face is present }
$$

$$
S \leq 1.3
$$

in which $T$ is the topographical factor for shallow soil slides; $C_{r}$ is the critical value for triggering these slides. For sub-area 1 to 4 in Fig. 7, the critical value $C_{r}$ is 0.73 , $0.78,0.83$, and 0.87 , respectively. The Eq. 7 shows the $U$ is the most sensitive factor and $C$ is less sensitive. This may because the slope gradient is large, and the landslide is in a few meters long. These result more runoff on the surface during a rainfall event, and less subsurface water converged by the lateral concavity to increase groundwater height, which is more important to decrease the slope stability.

Fig. 8 a.- d. shows the relationship of slope angle factor $S$ and combined factor $G+F$ (upslope factor $U$ and crosssection factor $C$ ) using the topographical factor with Eq. 7 10. In Fig. 8, the free-face factor $F$ is included in the data. In Fig. 7 it is difficult to predict the triggering of a shallow landslide without the introduction of the minimum slope angle $S$ at a particular site and for a particular rainfall. In Eq. 7 - 10, there is no minimum slope angle for assessing the stability of a slope. With the introduction of a limited value of $G+F$ (0.46), the minimum slope angle is not needed. The threshold can be described using only the linear function: $S+1.8 U+0.8 C+F=C_{\mathrm{r}}$ (Fig. 8). However these threshold 

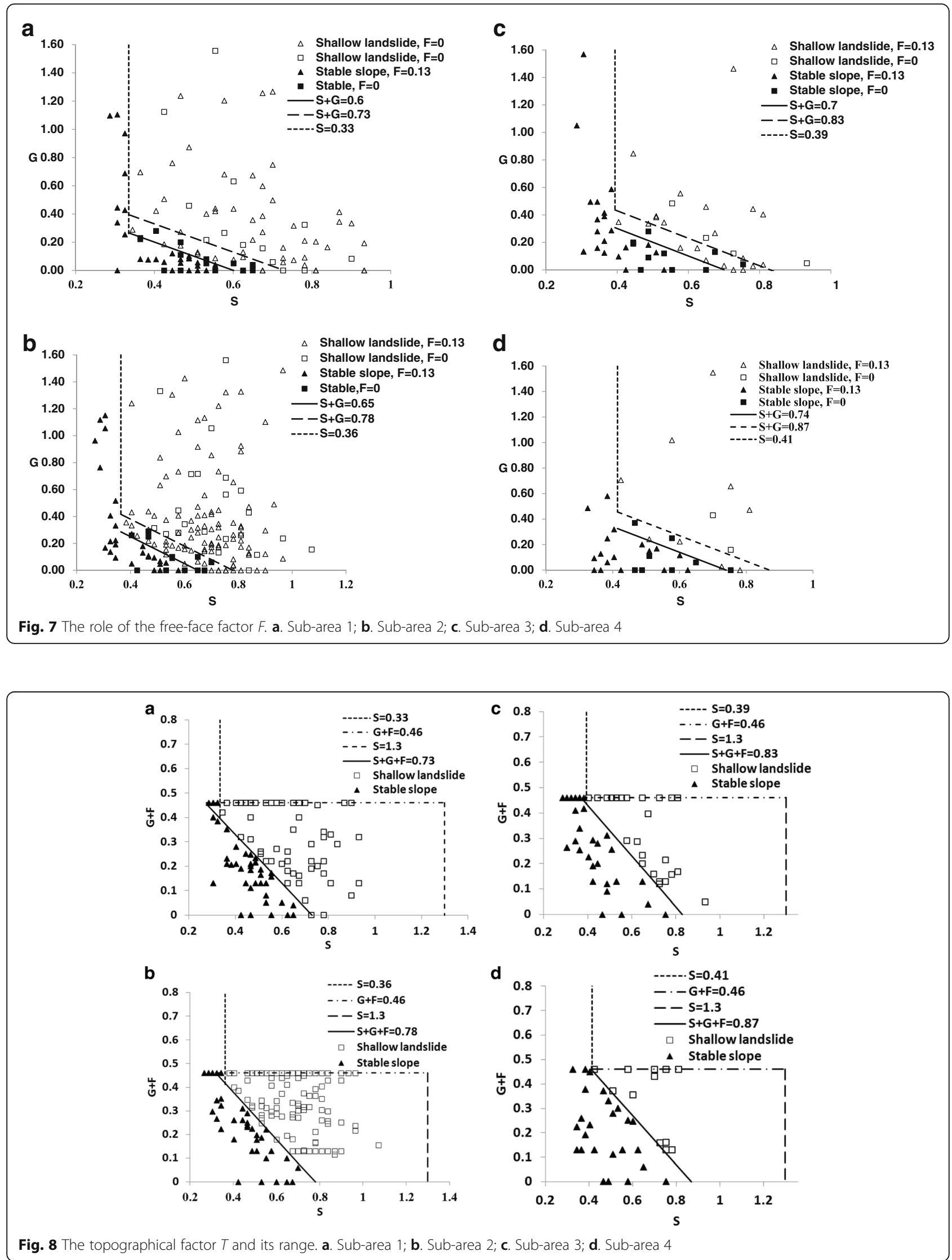
functions do not separate completely in all cases landslide sites from stable sites except in sub-area 4 (Fig. 8d). In subarea 1,2 , and 3 , a few data predicted wrongly stable slopes. The prediction may fail also at some sites with large critical value $\left(C_{r}>0.87\right)$. Nevertheless it is easy to assess the topographical factor $T$ with Eqs. 7-10 and to predict the stability of the slope without the use of the minimum slope angle. Sub-area 1, 2 and 3 show that there is only a small chance for a miss classification.

\section{Validation}

Many shallow landslides are triggered worldwide each year. Validation areas were selected only on the basis of availability of high-resolution digital elevation models in areas suceptable for shallow soil slides. The scale of the map for the field work or indoor analysis is depended the scale of landslides. For example, for the shallow landslides of Dayi area, the slips are a few meters long by a few meters wide. The better contour interval of map is $2 \mathrm{~m}$, and the better scale of the map is 1: 2000 . Previous field work in these areas allows us to obtain the topographical factors for these landslides. To test the topographical model, some stable slopes which are shallow landslide-prone were selected. Fig. 9 shows the boundaries for $A, A u, A_{R}, A_{L}$ for potential landslide area for given contour lines. For given contour lines, the definition of the boundaries for $A, A u, A_{R}$, and $A_{L}$ for potential landslide area as follow: 1) One can select a large slope gradient in the longitudinal section, and connect this section with a gentler upslope gradient, or with a hollow in a cross-section, or a free-face of the slope in the longitudinal section, or a combination of two, or three of these important topographical factors. 2) Then the boundaries for $A$ is needed to determine. The top boundary of $A$ is the contour line before the distance of contour lines increasing (see Fig. 9). If there is no gentler upslope gradient, i.e. the distance of contour lines of upslope is the same with or less than the distance of contour lines of $A$, the top boundary of $A$ is the same level of the top contour line of a hollow in a cross-section. The bottom boundary of $A$ is the contour line before the distance of contour lines decresing (see Fig. 9). If there is no free-face of the slope, i.e. the distance of contour lines of downslope is the same with or more than the distance of contour lines of $A$, the bottom boundary of $A$ is the same level of the bottom contour line of a hollow in a cross-section. The left side and right side boundaries of $A$ are the boundaries of flat part between the hollows in cross-section (see Fig. 9). If there is only one hollow or no hollow, the left side and right side boundaries of $A$ are just below the left side and right side boundaries of $A u$. 3) The top boundary of $A u$ is the contour line before the distance of contour lines increasing (see Fig. 9). The left side and right side

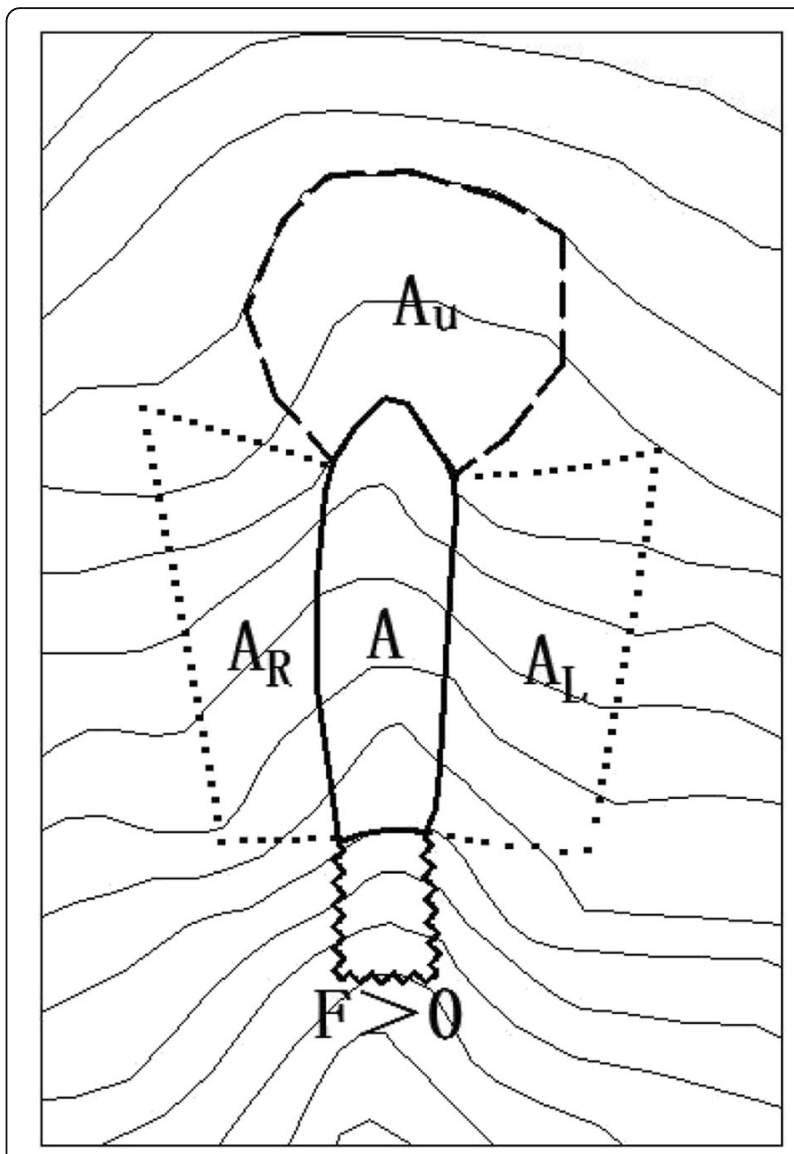

Fig. 9 The topographical schematic sketch of a potential shallow landslide and its surrounding topography for given contour lines

boundaries of $A u$ are the edges of the upstream contributing area which induced convergence of subsurface water flow (see Fig. 9). 4) The bottom lines of $A_{R}$ and $A_{L}$ are the same level of the bottom line of $A$. The top lines of $A_{R}$ and $A_{L}$ are the edges of the lateral concavity which induced convergence of subsurface water flow. The left boundary of $A_{L}$ or the right boundary of $A_{R}$ is the outside edge of the hollow (see Fig. 9).

Constant rainfall and geological conditions within one area are assumed because these study areas are relativly small. So the only factor for triggering shallow landslide is the topographical factor given by Eqs. 7-10.

\section{Validation in Tennessee Valley, Marin County, California, USA}

The Marin County catchment covers $1.2 \mathrm{~km}^{2}$ in the Tennessee Valley area of the Marin Headlands just north of San Francisco, California. The catchment is underlain by stacked thrust sheets composed of Cretaceous greenstone, greywacke, and cherts of the Franciscan Complex. The area has a Mediterranean climate with a mean annual rainfall of about $760 \mathrm{~mm}$. Landslidings is an important sediment transport process on steeper slopes and in topographical 
hollows, and overland flow and seepage erosion dominate on lower-gradient slopes. Aerial photography and field inspection identified 43 landslide scars, most of which occurred during or since the storms in 1974. The maximum scar size is roughly $10 \mathrm{~m}$ wide; the slides have a length of around $20 \mathrm{~m}$ and a depth around $1 \mathrm{~m}$. Most of the shallow landslides occurred in soil and some scoured until the bedrock. Almost all scars were located at steep parts of the catchment. The digital elevation data set has contours with an interval of $5 \mathrm{~m}$. Soil thickness varies from 0.1 to $0.5 \mathrm{~m}$ on topographic noses to depths until $4.0 \mathrm{~m}$ in topographic hollows (Montgomery and Dietrich 1994).

Form the digital elevation data (Fig. 4a) provided by Montgomery and Dietrich (1994), only 41 shallow landslides could be detected. The topographical factors of 41 shallow landslides and 12 potential sites without shallow landslides were determined using the digital elevation data. Generally the $T$-value of shallow landslides was larger than the $T$-value of stable slopes. Because the triggered rainfalls for these landslides were different, the critical $C_{r}$ values are different. Two critical values were proposed for separating the shallow landslide sites and stable slope sites (see Fig. 10): $C_{r a}=0.51, C_{r b}=0.67$. The threshold lines with these critical values were constructed as follows: below the line $T=0.67$ lie all the "no landslides" (except one). Above the $T=0.51$ line lie all the landslides. When $T \leq 0.51$, the possibility of shallow landslide is low; When $0.51<T \leq 0.67$, the possibility of shallow landslide is medium; When $T>0.67$, the possibility of shallow landslide is high. The critical value $C_{r b}$ is $31.3 \%$ higher than the critical value $C_{r a}$, which shows a moderate performance of the validated model. Table 1 shows the numbers and percentages of shallow landslides and no shallow landslides in three classes. All the points with $T>0.67$ are shallow landslides except one point. All the points with shallow

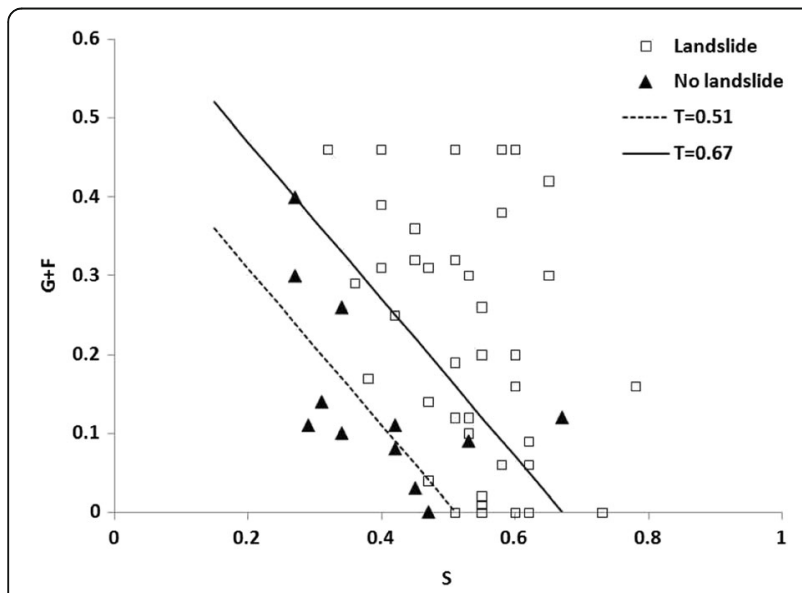

Fig. 10 The validation in Tennessee Valley Map showing shallow landslides and the probability
Table 1 The numbers and percentages of shallow landslide (SL) and no shallow landslide (no SL) in the three classes in Tennessee Valley

\begin{tabular}{lllll}
\hline $\begin{array}{l}\text { Number and percentage } \\
\text { of } S L \text { or no } S L\end{array}$ & $\begin{array}{l}\text { Number } \\
\text { of SL }\end{array}$ & $\begin{array}{l}\text { Percentage } \\
\text { of } S L(\%)\end{array}$ & $\begin{array}{l}\text { Number } \\
\text { of no SL }\end{array}$ & $\begin{array}{l}\text { Percentage } \\
\text { of no SL (\%) }\end{array}$ \\
\hline$T \leq 0.51$ & 0 & 0 & 6 & 50 \\
$0.51<T \leq 0.67$ & 14 & 34.1 & 5 & 41.7 \\
$T>0.67$ & 27 & 65.9 & 1 & 8.4 \\
\hline
\end{tabular}

landslides are located in the domain $T>0.51$. Almost all the points $(91.6 \%)$ without shallow landslides are located in the domain $T \leq 0.67$, and more than half of these points (50\%) are located in the domain $T \leq 0.51$. The topographical factor in three classes is applicable in Tennessee Valley.

\section{Validation in Mettman ridge, Oregon, USA}

The Mettman Ridge occupies $0.3 \mathrm{~km}^{2}$ in the Coast Range just north of Coos Bay, Oregon. The area is highly dissected and characterized by narrow ridge-tops and steep slopes, which is typical in the Oregon Coast Range. Bedrocks consist of gently dipping Eocene sandstone. The area has a maritime climate, and receives approximately $1500 \mathrm{~mm}$ of precipitation annually. Nineteen shallow landslides occurred in the Mettman Ridge catchment in the period between forest clearance in 1987 and the summer of 1992. Typical dimensions of the shallow landslides are in the order of $5 \mathrm{~m}$ by $10 \mathrm{~m}$ with a depth of about $1.5 \mathrm{~m}$. Digital elevation data were generated from a $1: 4800$ scale topographical map of the catchment with a 5-m contour interval. The soil in this area is silty sand and ranges in thickness from roughly 0.1 to $0.5 \mathrm{~m}$ on topographic noses to depths until $2 \mathrm{~m}$ in topographic hollows (Montgomery and Dietrich 1994).

The topographical factors of 19 shallow landslides and 10 landslide-prone sites, were obtained by the digital elevation data. Generally the $T$-value of shallow landslides is larger than the $T$-value of stable slopes. Because the triggering rainfalls were different in 1987 and 1992, the critical values $\left(C_{r}\right.$; in Eq. 7$)$ were different. Two critical values were proposed for separating the sites with shallow landslides and the sites susceptible to sliding (see Fig. 11): $C_{r c}=0.56, C_{r d}=0.73$. Below the line $T=0.73$ lie all the "no landslides" (except one). Above the $T=0.56$ line lie all the landslides (except one). The possibility for shallow landsliding are low, medium or high for respectively $T \leq 0.56 ; 0.56<T \leq 0.73 ; T>0.73$. The critical value $C_{r d}$ is $30.4 \%$ higher than the critical value $C_{r c}$, which shows a moderate performance of the validated model. Table 2 shows the numbers and percentages of shallow landslides and no shallow landslides for the three classes.

All the points beyond the line of $T>0.73$ are shallow landslides except one point. Almost all the points 


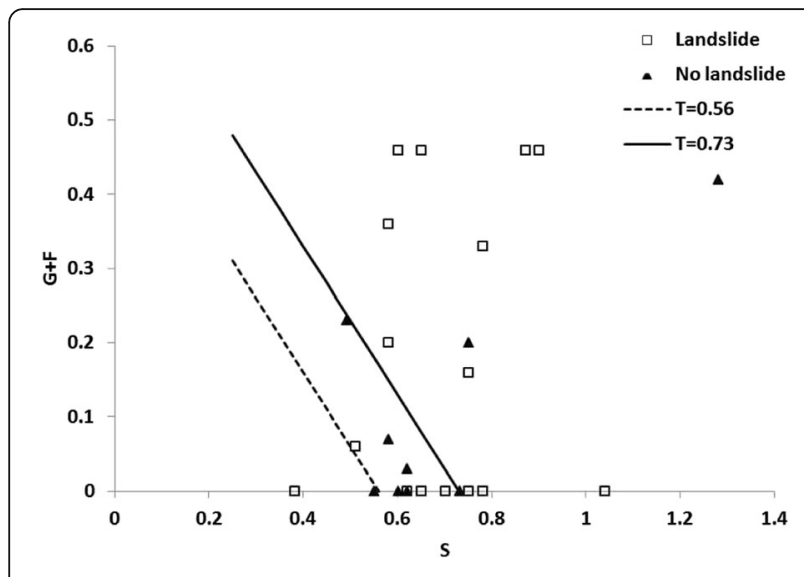

Fig. 11 The validation in Mettman Ridge

(94.7\%) with shallow landslides are located in the domain $T>0.56$. Most of the points $(80 \%)$ without shallow landslides are located in the domain $T \leq 0.73$, and $10 \%$ of these points are located in the domain $T \leq 0.56$. The topographical factor is a failrly good indicator for the assessment of landslide probability in three classes in Mettman Ridge.

\section{Validation in Split Creek, Washington, USA}

The Split Creek occupies $0.6 \mathrm{~km}^{2}$ of the north flank of the Huelsdonk Ridge on the South Fork of the Hoh River in the Olympic Peninsula. The area is characterized by steep, unglaciated tributaries that drain into a wide glaciated valley filled with glacial outwash and Holocenc alluvial sediments. Huelsdonk Ridge is underlain by steeply dipping, folded and faulted Oligocene to upper Eocene sandstones. The area receives 4000 to $5000 \mathrm{~mm} / \mathrm{yr}$. of rainfall annually. The soils, which occurred on these sandstones in this area consist of silty sands. Soil thickness averages about $1 \mathrm{~m}$, although soils are shallower on topographic noses and thicker in hollows. Digital elevation data with a 5-m contour interval were generated from color aerial photographs using a stereo-digitizer. Landslides visible on color aerial photographs flown in 1990 were drawn on this base map. In the west fork of Split Creek, nine shallow landslides were mapped by Montgomery and Dietrich (1994).

Table 2 The numbers and percentages of shallow landslide (SL) and no shallow landslide (no SL) in the three classes in Mettman Ridge

\begin{tabular}{lllll}
\hline $\begin{array}{l}\text { Number and percentage } \\
\text { of } S L \text { or no } S L\end{array}$ & $\begin{array}{l}\text { Number } \\
\text { of SL }\end{array}$ & $\begin{array}{l}\text { Percentage } \\
\text { of SL (\%) }\end{array}$ & $\begin{array}{l}\text { Number } \\
\text { of no SL }\end{array}$ & $\begin{array}{l}\text { Percentage } \\
\text { of no SL }(\%)\end{array}$ \\
\hline$T \leq 0.56$ & 1 & 5.3 & 1 & 10 \\
$0.56<T \leq 0.73$ & 5 & 26.3 & 7 & 70 \\
$T>0.73$ & 13 & 68.4 & 2 & 20 \\
\hline
\end{tabular}

The topographical factors of 9 shallow landslides and 10 potential sites were determined using the digital elevation data. Generally the $T$-values of shallow landslides calculated with Eq. 7 are larger than the $T$-values of stable but vulnerable slopes. Because the triggering rainfalls for these landslides were different, the critical values $\left(C_{r}\right)$ were different. Two critical values were proposed for separating the shallow landslides and actual stable but susceptible slopes (see Fig. 12): $C_{r e}=0.66, C_{r f}=0.86$. Below the line $T=0.86$ lie all the "no landslides" (except one). Above the $T=0.66$ line lie all the landslides. The possibility for shallow landsliding are low, medium or high for respectively $T \leq 0.66 ; 0.66<T \leq 0.86 ; T>0.86$. The critical value $C_{r f}$ is $30.3 \%$ higher than the critical value $C_{r e}$, which shows a moderate performance of the validation model. Table 3 shows the numbers and percentages of shallow landslides and no shallow landslides in three probability classes. All the points beyond the line of $T>0.86$ are shallow landslides except one point. All the points with shallow landslides are located in the domain $T>0.66$. Almost all the points (90\%) without shallow landslides are located in the domain $T \leq 0.86$, and half of these points are located in the domain $T \leq 0.66$. The topographical factorT is a usefull indicator to predict the possibility of shallow landsliding in Split Creek.

\section{Validation in Hofu, Japan}

The catchment occupies $0.18 \mathrm{~km}^{2}$ in the Hofu city area in Japan. The soils consist of weathered granites. The soil thickness is between 0.06 to $5.4 \mathrm{~m}$ (Akiyama et al. 2014). Digital elevation data with a 5-m contour interval is available. Akiyama et al. (2014) searched for the shallow landslides in an area of $0.064 \mathrm{~km}^{2}$ and found eight shallow landslides. There were 16 shallow landslides in the area of $0.18 \mathrm{~km}^{2}$ detected in this study with the photos provided by Akiyama et al. (2014). A heavy rainfall happened in July $20-21,2009$. The total precipitation was

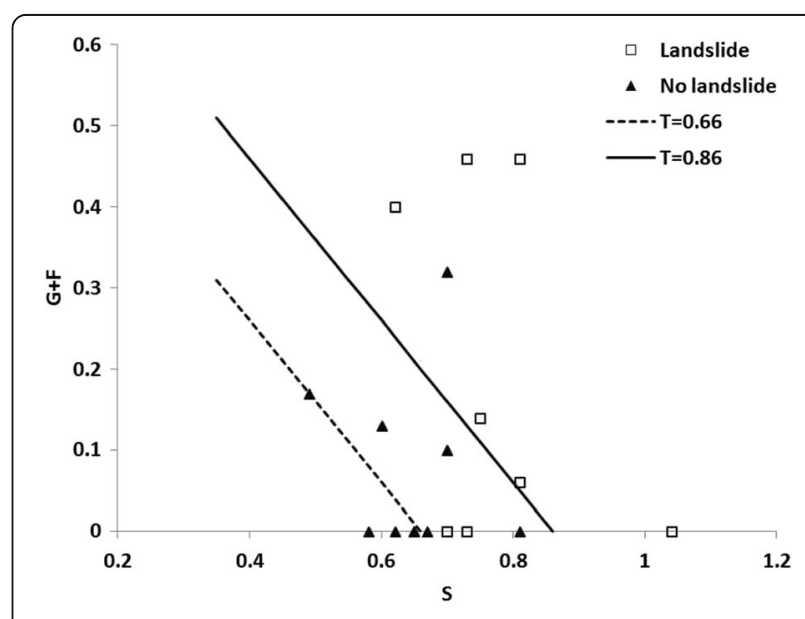

Fig. 12 The validation in Split Creek 
Table 3 The numbers and percentages of shallow landslide (SL) and no shallow landslide (no SL) in the three classes in Split Creek

\begin{tabular}{lllll}
\hline $\begin{array}{l}\text { Number and percentage } \\
\text { of } S L \text { or no } S L\end{array}$ & $\begin{array}{l}\text { Number } \\
\text { of SL }\end{array}$ & $\begin{array}{l}\text { Percentage } \\
\text { of } S L(\%)\end{array}$ & $\begin{array}{l}\text { Number } \\
\text { of no SL }\end{array}$ & $\begin{array}{l}\text { Percentage } \\
\text { of no SL (\%) }\end{array}$ \\
\hline$T \leq 0.66$ & 0 & 0 & 5 & 50 \\
$0.66<T \leq 0.86$ & 3 & 33.3 & 4 & 40 \\
$T>0.86$ & 6 & 66.7 & 1 & 10 \\
\hline
\end{tabular}

$330 \mathrm{~mm}$ in 2 days. Some shallow landslides were triggered during this period (Akiyama et al. 2014).

The topographical factors of 16 shallow landslides and 9 sites without shallow landslides but landslide-prone were obtained from the digital elevation data. Generally the $T$-value of shallow landslides is larger than the $T$ value of the selected stable slopes. Because the triggered rainfalls for these landslides were different, the critical values $C_{r}$ are different. Two critical values were proposed for separating the shallow landslides and stable slopes (see Fig. 13): $C_{r g}=0.55, C_{r k}=0.71$. Below the line $T=0.71$ lie all the "no landslides" (except two). Above the $T=0.55$ line lie all the landslides. The possibility for shallow landsliding are low, medium or high for respectively $T \leq 0.55 ; 0.55<T \leq 0.71 ; T>0.71$. The critical value $C_{r k}$ is $29.1 \%$ higher than the critical value $C_{r g}$, which shows a moderate performance of the validated model. Table 4 shows the numbers and percentages of shallow landslides and no shallow landslides in three probability classes. All the points beyond the line of $T>0.71$ are shallow landslides except two points. All the points with shallow landslides are located in the domain $T>0.55$. Most of the points (77.8\%) without shallow landslides are located in the domain $T \leq 0.71$, and $33.3 \%$ of these points are located in the domain $T \leq 0.55$. The topographical factorT is a usefull indicator to predict the possibility of shallow landsliding in Hofu.

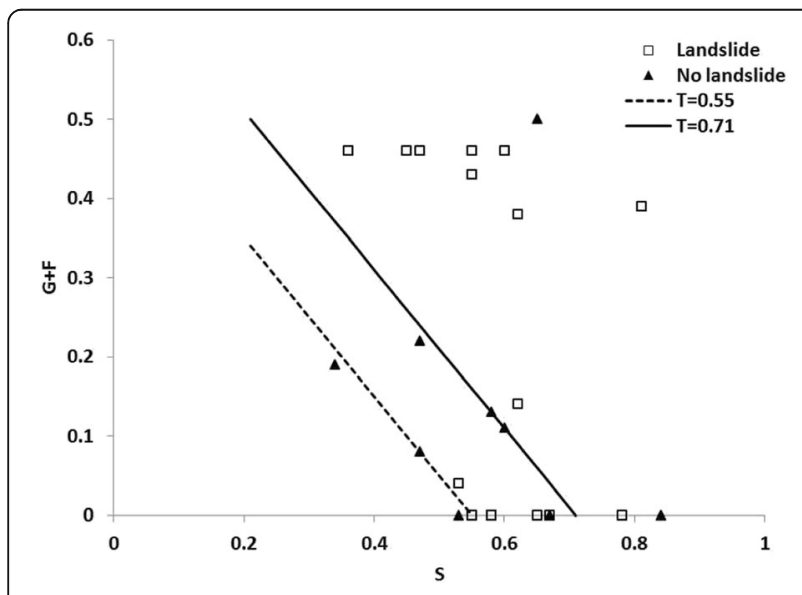

Fig. 13 The validation in Hofu
Table 4 The numbers and percentages of shallow landslide (SL) and no shallow landslide (no SL) in the three classes in Hofu

\begin{tabular}{lllll}
\hline $\begin{array}{l}\text { Number and percentage } \\
\text { of } S L \text { of no } S L\end{array}$ & $\begin{array}{l}\text { Number } \\
\text { of SL }\end{array}$ & $\begin{array}{l}\text { Percentage } \\
\text { of } S L(\%)\end{array}$ & $\begin{array}{l}\text { Number } \\
\text { of no SL }\end{array}$ & $\begin{array}{l}\text { Percentage } \\
\text { of no SL (\%) }\end{array}$ \\
\hline$T \leq 0.55$ & 0 & 0 & 3 & 33.3 \\
$0.55<T \leq 0.71$ & 6 & 37.5 & 4 & 44.4 \\
$T>0.71$ & 10 & 62.5 & 2 & 22.2 \\
\hline
\end{tabular}

On the other hand, the validation fails to predict shallow landslides in pyroclastic fall deposits in the Fukushima area, Japan, which were triggered during a rainstorm of Sep. 10 to 11, 1998 (Chigira et al. 2004). This is because the the shallow landslides in the pyroclastic fall deposits area has no relationship with any topographic factor (Chigira 2015).

\section{Quick and primary assessment}

The occurrence of landslides is controlled by various spatial and climatic factors, such as geology, topography, hydrogeological conditions, vegetation and rainfall (Park et al. 2013). The critical values $C_{r}$ to assess this topographical factor appeared to be different in our test area and the various validation areas in the USA and Japan because of the difference in geological conditions and rainfall conditions. So does the slope angle factor $S$. However the critical values differ not too much in the investigated areas. From the critical values in the Dayi area and the critical values of $C_{r 1}$, $C_{r a}, C_{r c}, C_{r e}, C_{r g}$, and $C_{r 2}, C_{r b}, C_{r d}, C_{r f} C_{r k}$ in USA and Japan, one can conclude that shallow landslides have a low probability to be triggered when the topographical factor is less than 0.51 and high trigger probability when the topographical factor is larger than 0.86 . So in the range of $0.51<T<0.86$ is the domain where most shallow landslides may occur in these areas. When we include other areas we probably have to extent the limits of probability of shallow landsliding due to a large variation in geological conditions and rainfall. A minmum value of $C_{r L}=0.5$, and a maxmum value of $C_{r H}=0.9$ may be a good choise for a quick and primary assessment of the possibility of shallow landsliding, ignoring the variation in geological and rainfall conditions. Because the range $0.5<T<0.9$ is large, three critical values to calculate the $T$ factor are proposed: $C_{r L}=0.5, C_{r M}=0.7$, and $C_{r H}=0.9$. When $T \leq 0.5$, the possibility of shallow landslide is very low; When $0.5<T \leq 0.7$, the possibility of shallow landslide is low; When $0.7<T \leq 0.9$, the possibility of shallow landslide is medium; When $T>0.9$, the possibility of shallow landsliding is high. The critical value $\mathrm{C}_{\mathrm{rH}}$ is $80 \%$ higher than the critical value $C_{\mathrm{rL}}$, and the critical value $\mathrm{C}_{\mathrm{rM}}$ is $40 \%$ higher than the critical value $C_{\mathrm{rL}}$, which shows a moderate performance of the assessment model. Table 5 shows the numbers and percentages of shallow landslides and no shallow landslides in four classes for the Dayi area and the USA 
Table 5 The numbers and percentages of shallow landslide (SL) and no shallow landslide (no SL) in the four classes

\begin{tabular}{|c|c|c|c|c|c|}
\hline & $\mathrm{T} \leq 0.5$ & $0.5<\mathrm{T} \leq 0.7$ & $0.7<\mathrm{T} \leq 0.9$ & $\mathrm{~T}>0.9$ & Tota \\
\hline Possibility & $\begin{array}{l}\text { Very } \\
\text { low }\end{array}$ & Low & Medium & High & \\
\hline $\begin{array}{l}\text { Numbers of SL } \\
\text { in Dayi }\end{array}$ & 0 & 0 & 69 & 161 & 230 \\
\hline $\begin{array}{l}\text { Percentages of } \\
\text { SL in Dayi (\%) }\end{array}$ & 0 & 0 & 30 & 70 & 100 \\
\hline $\begin{array}{l}\text { Numbers of no } \\
\text { SL in Dayi }\end{array}$ & 9 & 65 & 64 & 0 & 138 \\
\hline $\begin{array}{l}\text { Percentages of no } \\
\text { SL in Dayi (\%) }\end{array}$ & 6.5 & 47.1 & 46.4 & 0 & 100 \\
\hline $\begin{array}{l}\text { Numbers of SL } \\
\text { in TV }\end{array}$ & 0 & 18 & 17 & 6 & 41 \\
\hline $\begin{array}{l}\text { Percentages of } \\
\text { SL in TV (\%) }\end{array}$ & 0 & 43.9 & 41.5 & 14.6 & 100 \\
\hline $\begin{array}{l}\text { Numbers of no } \\
S L \text { in TV }\end{array}$ & 5 & 6 & 1 & 0 & 12 \\
\hline $\begin{array}{l}\text { Percentages of } \\
\text { no SL in TV (\%) }\end{array}$ & 41.7 & 50 & 8.3 & 0 & 100 \\
\hline $\begin{array}{l}\text { Numbers of } S L \\
\text { in } M R\end{array}$ & 1 & 4 & 4 & 10 & 19 \\
\hline $\begin{array}{l}\text { Percentages of } \\
\text { SL in MR (\%) }\end{array}$ & 5.3 & 21 & 21 & 52.7 & 100 \\
\hline $\begin{array}{l}\text { Numbers of no } \\
S L \text { in } M R\end{array}$ & 1 & 5 & 3 & 1 & 10 \\
\hline $\begin{array}{l}\text { Percentages of no } \\
\text { SL in MR (\%) }\end{array}$ & 10 & 50 & 30 & 10 & 100 \\
\hline $\begin{array}{l}\text { Numbers of } S L \\
\text { in SC }\end{array}$ & 0 & 2 & 3 & 4 & 9 \\
\hline $\begin{array}{l}\text { Percentages of } \\
\text { SL in SC (\%) }\end{array}$ & 0 & 22.2 & 33.3 & 44.4 & 100 \\
\hline $\begin{array}{l}\text { Numbers of no } \\
\text { SL in SC }\end{array}$ & 0 & 6 & 3 & 1 & 10 \\
\hline $\begin{array}{l}\text { Percentages of } \\
\text { no SL in SC (\%) }\end{array}$ & 0 & 60 & 30 & 10 & 100 \\
\hline $\begin{array}{l}\text { Numbers of SL } \\
\text { in Hofu }\end{array}$ & 0 & 6 & 3 & 7 & 16 \\
\hline $\begin{array}{l}\text { Percentages of } \\
\text { SL in Hofu (\%) }\end{array}$ & 0 & 37.5 & 18.7 & 43.8 & 100 \\
\hline $\begin{array}{l}\text { Numbers of no } \\
\text { SL in Hofu }\end{array}$ & 0 & 6 & 2 & 1 & 9 \\
\hline $\begin{array}{l}\text { Percentages of no } \\
\text { SL in Hofu (\%) }\end{array}$ & 0 & 66.7 & 22.2 & 11.1 & 100 \\
\hline $\begin{array}{l}\text { Numbers of SL } \\
\text { in Total }\end{array}$ & 1 & 30 & 96 & 188 & 315 \\
\hline $\begin{array}{l}\text { Percentages of } \\
\text { SL in Total (\%) }\end{array}$ & 0.3 & 9.5 & 30.5 & 59.7 & 100 \\
\hline $\begin{array}{l}\text { Numbers of no } \\
\text { SL in Total }\end{array}$ & 15 & 88 & 73 & 3 & 179 \\
\hline $\begin{array}{l}\text { Percentages of no } \\
\text { SL in Total (\%) }\end{array}$ & 8.4 & 49.2 & 40.8 & 1.7 & 100 \\
\hline
\end{tabular}

areas. Almost all sites (99.7\%) beyond the line of $T>0.5$ are shallow landslides except one point, and most sites (90.2\%) with shallow landslides are located in the domain $T>0.7$. Almost all sites (98.3\%) without shallow landslides are located in the domain $T \leq 0.9$, and more than half of these points (57.6\%) are located in the domain $T \leq 0.7$. The topographical factor subdivided in four classes is a good indicator in these areas.

\section{Rainfall factor in the shallow soil slips}

Rainfall is the major threshold for triggering shallow landslides. Unfortunately, there is no detailed rainfall information corresponding to shallow landslides triggered in the validation areas. In the Dayi area, we were able for one event on June 5 and 6, 2011, using two available meteorological stations, to distinguish four sub-areas with different rainfall amounts leading to different critical values $C_{r}$. This delivered a primary study on the effect of rainfall on the topographical factor $T$.

The landslides in question are most commonly triggered by climatic events, such as high intensity rainstorms or the succession of medium intensity rainstorms in a wet season (Hennrich and Crozier 2004). In some research work, the duration of rainfall is used as one rainfall factor (Caine 1980, Godt et al. 2008, Baum et al. 2005). These authors use another rainfall factor: the mean rainfall intensity in the rainfall intensity-duration model to predict the occurrence of shallow landslides. Godt et al. (2008) pointed out that rainfall of high intensity and short duration has a limited effect on landslides triggered in thicker soil mantles. In the study area of Dayi, most shallow landslides have a thickness of less than $1 \mathrm{~m}$. In that case the rainfall of high intensity and short duration does have an effect on the triggering of shallow landslides. In this paper, the intensity and the cumulative rainfall are chosen as factors for the threshold value of shallow landsliding. Yu et al. (2016) used the $1 \mathrm{~h}$ intensity and the cumulative rainfall before a debris flow event to predict the triggering of debris flows during the events of June 6, 2011 in the Dayi area. Since these debris flows are triggered in most cases by shallow landslides (Fig. 1), the rainfall threshold proposed by $\mathrm{Yu}$ et al. (2016) can be introduced for shallow landslides in the study area:

$$
R={ }^{*} /_{R_{0}}=(B+5.5 I) / R_{0}
$$

in which $R$ is the rainfall factor; $R *$ is the critical rainfall (in $\mathrm{mm}) ; R_{O}$ is the annual precipitation of the site $(\mathrm{mm})$; $B$ is the cumulative precipitation in the period before the triggering of the shallow landslide (in $\mathrm{mm}$ ); $I$ is the rainfall in $1 \mathrm{~h}$ before the start of the shallow landslide (in $\mathrm{mm}$ ). The annual precipitation $R_{O}$ for each shallow landslide is obtained from the spatial distribution of 
annual rainfall in the study area. The $R_{0}$ is introduced to normalize the rainfall threshold (Aleotti 2004).

The rainfall data of the area downstream of Dayi, such as the rainfall intensity $I$, and the cumulative rainfall $B$, was interpolated between the rainfall data of Dayi and Xintun (Fig. 2). The rainfall intensity and total accumulated rainfall during June $5-6$ were generally increasing from south to north. The rainfall intensity and total accumulated rainfall in sub-area 1 may be larger than the values measured in Dayi town, which makes it difficult to estimate $I$ and $B$ in sub-area 1 . Therefore this area is excluded for the study of the rainfall factor $R$.

Fig. 14 shows the relationship between the topographical factor $T$ and the rainfall factor $R$ in the area downstream of Dayi. Without the data in the sub-area 1, only 162 points with shallow landslides and 96 points with stable slopes in sub-area 2, 3, and 4 were plotted in Fig. 14. One can define the relationship between the $T$-factor and the $R$-factor in the determination of presence or absence of shallow landslides in the Dayi area as follows:

$$
\mathrm{P}=\mathrm{RT}^{1.2} \geq \mathrm{C}_{\mathrm{R}}
$$

in which $P$ is the primary prediction factor, and $C_{R}$ is the critical value for the triggering of debris flows.

There are two critical values in Fig. 14: $C_{R a}=0.27$, $C_{R b}=0.30$. The two lines divide the figure into 3 domains: $P<0.27 ; 0.27 \leq P<0.30 ; P \geq 0.30$ with respectively low, medium and high possibility of occurrence of shallow landslides. Table 6 shows the distributions of shallow landslides and no landslides in the 3 domains. All the points beyond the line of $P \geq 0.30$ are shallow landslides and all the points under the line of $P<0.27$ are no landslides. All the points with shallow landslides are located in the zone $P \geq 0.27$, and most of the points (85.2\%) are located in the zone $P \geq 0.30$. All the points without shallow landslides are located in the zone $P<$

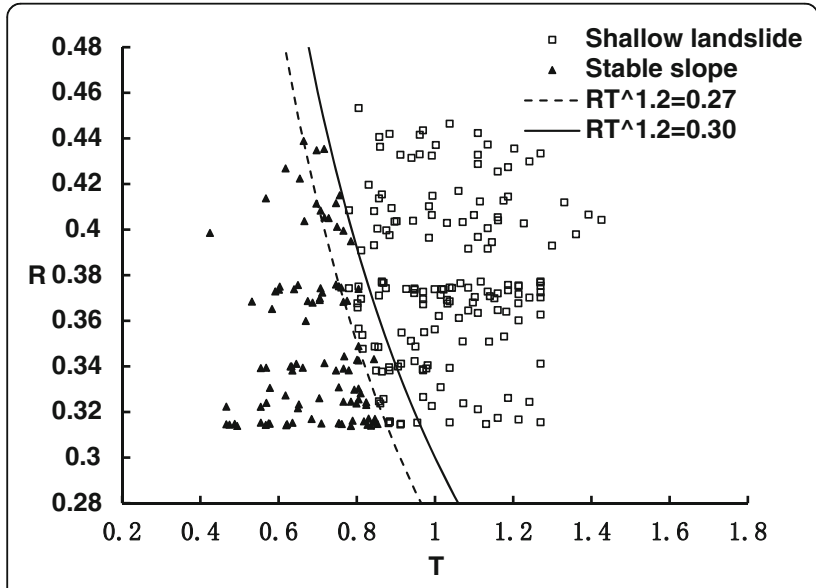

Fig. 14 The relationship of $T$ factor and $R$ factor
Table 6 The numbers and percentages of shallow landslide (SL) and no shallow landslide (no SL) assessment by $P$ factor in the three classes in Dayi

\begin{tabular}{lllll}
\hline $\begin{array}{l}\text { Number and percentage } \\
\text { of SL of no SL }\end{array}$ & $\begin{array}{l}\text { Number } \\
\text { of SL }\end{array}$ & $\begin{array}{l}\text { Percentage } \\
\text { of SL (\%) }\end{array}$ & $\begin{array}{l}\text { Number } \\
\text { of no SL }\end{array}$ & $\begin{array}{l}\text { Percentage } \\
\text { of no SL (\%) }\end{array}$ \\
\hline$P<0.27$ & 0 & 0 & 84 & 87.5 \\
$0.27 \leq P<0.30$ & 24 & 14.8 & 12 & 12.5 \\
$P \geq 0.30$ & 138 & 85.2 & 0 & 0 \\
\hline
\end{tabular}

0.30 , and most of the points $(87.5 \%)$ with no shallow landslides are located in the zone $P<0.27$ (see Table 6). The critical values in Eq. 12 only apply to the Dayi area because of its local geological conditions. The rainfall factor $R$ has almost the same importance as the topographical factor $T$ for the susceptibility for landsliding $(P)$. The critical value $C_{R \mathrm{a}}$ is $11.1 \%$ higher than the critical value $C_{R b}$ (Eq. 12), which shows a moderate performance of the prediction model.

\section{Discussion}

Montgomery and Dietrich (1994) indicated that slope gadient calculations using low-resolution data tend to produce too low values. Acquisition of high-quality, highresolution digital elevation data is important to allow the identification of potential shallow landslide source areas. The digital elevation data used in the validation process has a reasonable high-quality, but the 5-m contour interval may cause errors for the upslope factor and especially for the cross-section factor. Digital Elevation Models with Contour intervals of $2 \mathrm{~m}$ or even $1 \mathrm{~m}$, will give a more accurate assessment but are costly for larger areas.

A maximum value of 0.46 for the combined factor $(G+F)$ is chosen to simplify the assessment of the topographical factor $T$. But it may lead to more misclassifications because the presence of a minimum slope angle for shallow landslides in this simplified assessment is disgarded. More research should be conducted on this issue to revise the topographical factor to obtain better results in the future.

A lots of shallow landslides were triggered in a small area provided an unprecedented amount of data to establish a topographical factor for the assessment of shallow landslides in soil material (soil slips). These shallow landslides have a typical length and width of several meters and a depth of about $1 \mathrm{~m}$. The susceptibility of this kind of shallow landslides may be determined by the topographical factor $T$ proposed in this study, because (1): the critical water level for failure will be reached relatively fast in these shallow soils (around $1 \mathrm{~m}$ ) compared to more deeper soils. As a result, the upslope and crosssection factor (hollow) have a larger effect. (2): The lateral friction of the sides of the slides in these shallow soils are less, making the effect of the free-face of a topographical 
nose unimportant. The depths of shallow landslides in USA and Japan used for the validations process are in the range of 0.5 to $5 \mathrm{~m}$, but characteristic depths are less than $2 \mathrm{~m}$. This may be the reason for the satisfactory validations in these areas. More research is needed to validate the topographical factor $T$ as a predictor for shallow landslides with a depth of 2 to $5 \mathrm{~m}$.

The soils in this study occurred on siltstones and mudstones (Dayi), greenstones, greywackes, and cherts (Tennessee Valley), sandstones (Mettman Ridge), sandstones (Split Creek), granites (Hofu), so in general silty to sandy soils. More work should be conducted for other types of soil to find the suitable values for the topographical factor $T$ and rainfall factor $R$.

In this study an intensity-cumulative rainfall model was used for the rainfall factor instead of an intensity-duration model. However most studies on the influence of rainfall on triggering of shallow landslides are based on an intensity-duration model (Caine 1980, Godt et al. 2008, Baum et al. 2005). More work should be done to prove the validity of this intensity-cumulative rainfall model.

The rainfall parameter $R$ may affect the landslide area $A$, which in turns will affect the topographical parameters $U, C$, and $T$, respectively according to Eqs. (2) to (7). When the rainfall factor $R$ is large, the landslide area $A$ may increase, resulting the decreasing of the parameters $U, C$, and $T$. For this case, the primary prediction factor $P$ may still large enough to predict the triggering of shallow landslide because the increasing of $R$ is more, and the decreasing of $T$ is less according to Eqs. (7) and (12).

\section{Conclusions}

The large number of shallow landslide events in the Dayi area, Guizhou, China, triggered by a large rainfall event in June 2011, provided a good opportunity to study the influence of topographical factors on the triggering of shallow landslides. The geological conditions were uniform in this research area. The Dayi area was subdivided into four sub-areas with roughly identical rainfall conditions. In this way we could isolate and analyze the effect of the topographical factors on the possibility of shallow landsliding.

A new factor $T$ is proposed as a single topographical indicator, which can be used as an indicator for the triggering possibility of shallow landslides. Based on the annual precipitation at the site, the normalized rainfall $R$ was obtained from the cumulative rainfall, and the rainfall $1 \mathrm{~h}$ before the triggering. The relationship of the $T$ factor and the $R$ factor gives a primary threshold value for shallow soil slides. This relationship may be used for other areas with identical geological conditions.

The following conclusions can be drawn from our study:

(1) The major topographic factors related with the occurrence of shallow landslides are the slope angle factor, the upslope factor, the cross-section factor, and the free-face factor. The topographical factor $T$ is a combination of these factors. The probability of shallow landslides increases with increasing $T$-values.

(2) The role of the slope angles is more important than the role of the upslope factor, the cross-section factor, and the free-face factor. The major rainfall factors related with the occurrence of shallow landslides are the cumulative rainfall and the rainfall in $1 \mathrm{~h}$ before the shallow landslide. The probability of shallow landsliding increases with increasing $R$-values.

(3) The probability of shallow landsliding increases with increasing $P$-values, where $P$ is a combination of the $T$ factor and the $R$ factor. The topographical factor $T$ has almost the same influence than the rainfall factor $R$ on the probability of shallow landsliding.

\section{Acknowledgements}

This work was supported by by the Funds for Creative Research Groups of China (Grant No. 41521002), the National Natural Science Foundation of China (NSFC, contract number: 41672341) and the State Key Laboratory of Geohazard Prevention and Geoenvironment Protection Foundation (contract number: SKLGP2014Z012). We are grateful to Dr. Theo van Asch for having provided a very helpful review of the manuscript, and for help on the English editing of the manuscript.

\section{Authors' contributions}

BY conceived of the study, and participated in its design and coordination and drafted the manuscript. YZ carried out the field investigation and the data analysis, participated in the design of the study and performed the statistical analysis. YL carried out the field investigation and the data analysis. All authors read and approved the final manuscript.

\section{Competing interests}

The authors declare that they have no competing interests.

\section{Publisher's Note}

Springer Nature remains neutral with regard to jurisdictional claims in published maps and institutional affiliations.

Received: 23 September 2016 Accepted: 19 October 2017

Published online: 30 October 2017

\section{References}

Akiyama, R., A. Kinoshita, T. Uchida, T. Takahara, and T. Ishizuka. 2014. A method for assessing spatial patterns of rainfall-intensity duration thresholds for shallow landslides. In AGU Fall meeting, Dec. 15 - 19, abstract \#NH43A-3801. San Francisco: American Geophysical Union.

Aleotti, P. 2004. A warning system for rainfall-induced shallow failures. Engineering Geology 73: 247-265.

Baeza, C., and J. Corominas. 2001. Assessment of shallow landslide susceptibility by means of multivariate statistical techniques. Earth Surfaces Processes Landforms 26: 1251-1263.

Baum, R.L., J.A. Coe, J.W. Godt, E.L. Harp, M.E. Reid, W.Z. Savage, W.H. Schulz, D.L. Brien, A.F. Chleborad, J.P. McKenna, and J.A. Michael. 2005. Regional landslidehazard assessment for Seattle, Washington, USA. Landslides 2: 266-279.

Borga, M., G.D. Fontana, C. Gregoretti, and L. Marchi. 2002b. Assessment of shallow landsliding by using a physically based model of hillslope stability. Hydrological Processes 16: 2833-2851.

Caine, N. 1980. The rainfall intensity-duration control of shallow landslides and debris flows. Geografiska Annaler 62A (1/2): 23-27.

Chigira, M. 2015. Earthquake-induced landslides in the ring of fire. In The $4^{\text {th }}$ International Symposium on Mega Earthquake Induced Geo-diasasters and Long Term Effects, May 9 -13. Beijing: Science Press. 
Chigira, M., F. Duan, H. Yagi, and T. Furuya. 2004. Using an airborne laser scanner for the identification of shallow landslides and susceptibility assessment in an area of ignimbrite overlain by permeable pyroclastics. Landslides 1: 203-209.

Frattini, P., G. Crosta, and R. Sosio. 2009. Approaches for defining thresholds and return periods for rainfall-triggered shallow landslides. Hydrological Processes 23: 1444-1460.

Godt, J.W., R.L. Baum, W.Z. Savage, D. Salciarini, W.H. Schulz, and E.L. Harp. 2008. Transient deterministic shallow landslide modeling: Requirements for susceptibility and hazard assessments in a GIS framework. Engineering Geology 102: 214-226.

Hennrich, K., and M.J. Crozier. 2004. A Hillslope hydrology approach for catchment-scale slope stability analysis. Earth Surfaces Process Landforms 29: 599-610.

Meisina, C., and S. Scarabelli. 2007. A comparative analysis of terrain stability models for predictingshallow landslides in colluvial soils. Geomorphology 87: 207-223.

Montgomery, D. R., and W. E. Dietrich. 1994. A physically based model for the topographic control on shallow landsliding. Water Resources Research 30: 1153-1171.

Mulder, H., F. 1991. Assessment of landslide hazard. Doctoral Thesis. Faculty of Geographical Sciences, University of Utrecht, p 150.

O'Loughlin, E.M. 1986. Prediction of surface saturation zones in natural catchments by topographic analysis. Water Resources Research 22: 794-804.

Park, H.J., J.H. Lee, and I. Woo. 2013. Assessment of rainfall-induced shallow landslide susceptibility using a GIS-based probabilistic approach. Engineering Geology 161: 1-15.

Talebi, A., R. Uijlenhoet, and P. A. Troch. 2008. A low-dimensional physically based model of hydrologic control of shallow landsliding on complex hillslopes. Earth Surf. Process Landforms 33: 1964-1976.

Wang, S. 1999. Hazard of debris flow on slope and its control. The Chinese Journal of Geological Hazard and Control 10 (3): 45-48 (in Chinese with English abstract).

Wieczorek, G. F., R. C. Wilson, S. D. Ellen, M. E. Reid, and A. S. Jayko. 2007. Thirtyone years of debris-flow observation and monitoring near la Honda, California, USA. In Debris-flow hazards mitigation: Mechanics, prediction, and assessment, ed. Chen \& Major, 55-63. Netherlands: Millpress.

Yu, B., T. Wang, Y. Zhu, and Y., B. Zhu. 2016. Topographical and rainfall factors determining the formation of gully-type debris flows caused by shallow landslides in the Dayi area, Guizhou Province, China. Environmental Earth Sciences 75: 551.

\section{Submit your manuscript to a SpringerOpen ${ }^{\circ}$ journal and benefit from:}

- Convenient online submission

- Rigorous peer review

- Open access: articles freely available online

- High visibility within the field

- Retaining the copyright to your article

Submit your next manuscript at $\gg$ springeropen.com 